\title{
2020 Korean Society for the Study of Obesity Guidelines for the Management of Obesity in Korea
}

\begin{abstract}
Bo-Yeon Kim', Seon Mee Kang ${ }^{2}$, Jee-Hyun Kang ${ }^{3}$, Seo Young Kang ${ }^{4}$ Kyoung Kon Kim ${ }^{5}$, Kyoung-Bae Kim 6 , Bomtaeck Kim7, Seung Jun Kim ${ }^{8}$, Yang-Hyun Kim ${ }^{9}$, Jung-Hwan Kim ${ }^{10}$, Jae Hyun Kim ${ }^{11}$, Eun Mi Kim² ${ }^{12}$ Ga Eun Nam ${ }^{9}$ Ji Yeon Park ${ }^{13}$, Jang Won Son ${ }^{14}$, Yun-A Shin ${ }^{15}$, Hye-Jung Shin ${ }^{16}$, Tae Jung $\mathrm{Oh}^{17}$, Hyug Lee ${ }^{18}$, Eon-Ju Jeon ${ }^{19}$, Sochung Chung ${ }^{20}$, Yong Hee Hong ${ }^{21}$, Chong Hwa Kim ${ }^{22, * ;}$ Committee of Clinical Practice Guidelines, Korean Society for the Study of Obesity (KSSO)

'Division of Endocrinology and Metabolism, Department of Internal Medicine, Soonchunhyang University Bucheon Hospital, Soonchunhyang University College of Medicine, Bucheon; ${ }^{2}$ Department of Internal Medicine, Busan Paik Hospital, Inje University College of Medicine, Busan; ${ }^{3}$ Department of Family Medicine, Konyang University Hospital, Konyang University College of Medicine, Daejeon; ${ }^{4}$ International Healthcare Center, Asan Medical Center, Seoul; 5 Department of Family Medicine, Gil Medical Center, Gachon University College of Medicine, Incheon; ${ }^{6}$ Department of Physical Education, Korea Military Academy, Seoul; 7 Department of Family Practice and Community Health, Ajou University School of Medicine (AUSOM); ${ }^{8}$ Department of Psychiatry, Konyang University College of Medicine, Daejeon; ${ }^{9}$ Department of Family Medicine, Korea University College of Medicine, Seoul; ${ }^{10}$ Department of Family Medicine, Eulji Hospital, Eulji University School of Medicine, Seoul; "Department of Pediatrics, Seoul National University Bundang Hospital, Seoul National University College of Medicine, Seongnam; ${ }^{2}$ Department of Dietetics, Kangbuk Samsung Hospital, Seoul; ${ }^{13}$ Department of Surgery, Kyungpook National University Chilgok Hospital, School of Medicine, Kyungpook National University, Daegu; ${ }^{14}$ Division of Endocrinology and Metabolism, Department of Internal Medicine, Bucheon St Mary's Hospital, College of Medicine, The Catholic University of Korea, Bucheon; ${ }^{15}$ Department of Prescription and Rehabilitation of Exercise, College of Sport Science, Dankook University, Cheonan; ${ }^{16}$ Department of Pediatrics, National Medical Center, Seoul; " ${ }^{77}$ Department of Internal Medicine, Seoul National University Bundang Hospital, Seoul National University College of Medicine, Seongnam; ${ }^{18}$ Central St' Mary's Clinic Internal Medicine, Seoul; ${ }^{19}$ Division of Endocrinology and Metabolism, Department of Internal Medicine, Catholic University of Daegu School of Medicine, Daegu; ${ }^{20}$ Department of Pediatrics, Konkuk University Medical Center, Konkuk University School of Medicine, Seoul:; ${ }^{21}$ Department of Pediatrics, Soonchunhyang University Bucheon Hospital, Soonchunhyang University College of Medicine, Bucheon; ${ }^{22}$ Division of Endocrinology and Metabolism, Department of Internal Medicine, Sejong General Hospital, Bucheon, Korea
\end{abstract}

Obesity is a prevalent and complex disease. The prevalence of obesity in Korea increased from $29.7 \%$ in 2010 to $35.7 \%$ in 2018 , with the prevalence of abdominal obesity being $23.8 \%$ in 2018 . Obesity contributes to medical costs and socioeconomic burden due to associated comorbidities. The treatment and management of obesity is changing based on new clinical evidence. The 2020 Korean Society for the Study of Obesity Guideline for the Management of Obesity in Korea summarizes evidence-based recommendations and treatment guidelines.

Key words: Obesity, Clinical practice guidelines, Korea

\author{
Received February 28, 2021 \\ Reviewed April 13, 2021 \\ Accepted April 15, 2021 \\ ${ }^{*}$ Corresponding author \\ Chong Hwa Kim \\ (i) \\ https://orcid.org/0000-0002-4563-7772 \\ Division of Endocrinology and \\ Metabolism, Department of Internal \\ Medicine, Sejong General Hospital, \\ 28 Hohyeon-ro 489beon-gil, Sosa-gu, \\ Bucheon 14754, Korea \\ Tel: +82-32-340-1116 \\ Fax: +82-32-340-1236 \\ E-mail:drangelkr@hanmail.net
}

\section{INTRODUCTION}

The Korean Society for the Study of Obesity (KSSO) published a 2019 Obesity Fact Sheet based on data from the Korean National
Health Insurance Service, which stated that the prevalence of obesity in Korea increased from $29.7 \%$ in 2010 to $35.7 \%$ in 2018 . The prevalence of abdominal obesity among Korean adults in 2018 was $23.8 \%$ ( $28.1 \%$ for men and $18.2 \%$ for women), indicating a steady

Copyright (C) 2021 Korean Society for the Study of Obesity

() This is an Open Access article distributed under the terms of the Creative Commons Attribution Non-Commercial License (https://creativecommons.org/licenses/by-nc/4.0/) which permits unrestricted non-commercial use, distribution, and reproduction in any medium, provided the original work is properly cited. 
increase from $19.0 \%$ in $2009 .{ }^{1}$ Obesity is associated with metabolic abnormalities such as type 2 diabetes, dyslipidemia, insulin resistance, metabolic syndrome, gallbladder disease, coronary artery disease, hypertension, and cancer. There is an increased risk of comorbidities (directly linked with obesity) such as arthritis, back pain, and sleep apnea. Therefore, obesity is associated with medical and socio-economic burdens due to comorbidities. In addition, the treatment and management of obesity is changing, reflecting new clinical evidence.

The revised 2020 Obesity Treatment Guidelines (7th edition) was based on the previous 2018 Obesity Treatment Guidelines (6th edition), ${ }^{2}$ and included the latest research results. Levels of evidence and a variety of clinical situations were taken into account when formulating the recommended grades. In addition, changes and developments in the 2019 anti-obesity drug market were reflected in the revised guidelines.

This treatment guideline was organized into questions divided into nine major topics with the goal of increasing utilization in clinical practice among primary care physicians treating obese patients. The new revised guidelines summarize evidence-based recommendations and treatment guidelines. The levels of evidence were classified into A, B, C, and D (Table 1). The standards of the recommended grade were presented using a modified Grading of Recom- mendation Assessments, Development and Evaluation (GRADE) method $^{3}$ and the grades were divided into classes I, IIa, IIIb, and III. Recommendations with low levels of evidence, but clear benefits or high utilization rates in treatment according to user opinion survey results, were partially upgraded with the agreement of the treatment guidelines committee. In order to determine the strengths of recommendations, factors such as the level of evidence, the level of use at primary care sites reflecting benefits and risks, practicability, and acceptance were comprehensively considered (Table 1).

In this article, we introduce and briefly describe the 2020 Korean Society for the Study of Obesity (KSSO) Guideline for the Management of Obesity in Korea.

\section{RECOMMENDATIONS}

This clinical practice guideline informs the arc of the patient journey and the approach for clinical management of obesity in the primary care setting. The guideline recommendations are shown in Table 2 and include nine major themes: evaluation before obesity treatment, behavioral therapy, physical activity, nutrition therapy, pharmacotherapy, bariatric surgery, obesity in the elderly, obesity in children and adolescents, and metabolic syndrome. The purpose of the guideline is as follows. First, it helps practitioners, who are

Table 1. Levels of evidence and recommended grades

\section{Definition}

Level of evidence

A

B

C

D

Recommended grade

Class I

Class lla

Class Ilb

Class III
There is good research-based evidence to support the recommendation.

Data derived from at least 1 randomized controlled trial, meta-analysis or systematic review

There is fair research-based evidence to support the recommendation.

Data derived from at least 1 well designed cohort or case-control study without randomization

There is fair evidence but it is insufficient to support the recommendation.

Data derived from case series or observational studies

The recommendation is based on expert opinion and panel consensus.

Consensus of expert opinions based on experience

The recommendation is supported by level of evidence $A$.

Is recommended

Clinically important outcomes and the study population is representative of the population in the recommendation.

The recommendation is supported by level of evidence $B$.

Should be considered

Clinically important or validated surrogate outcomes.

The recommendation is supported by level of evidence $\mathrm{C}$ or $\mathrm{D}$. May be considered

The outcome is an unvalidated surrogate condition but clinically important outcomes.

The recommendation is supported by level of evidence $\mathrm{C}$ or $\mathrm{D}$.

Is not recommended

Outcome is an unvalidated surrogate for clinically important population, or the applicability of the study is irrelevant.

Data from Schünemann et al. ${ }^{3}$ 
Table 2. Recommendations for the management of obesity

Recommendation

Category of evidence and

strength of recommendation

Evaluation before obesity treatment

1. The definition for obesity in adults is $\mathrm{BMl} \geq 25 \mathrm{~kg} / \mathrm{m}^{2}$. Abdominal obesity is detected by measuring the waist circumference and is defined as $\geq 90 \mathrm{~cm}$ and $\geq 85 \mathrm{~cm}$ for adult men and women, respectively.

2. Obesity is classified into primary obesity, commonly known as simple obesity, and secondary obesity, which can be caused by genetics, endocrine diseases, and drugs.

3. Obesity increases the risk of type 2 diabetes, hypertension, dyslipidemia, coronary artery disease and metabolic syndrome, and increases total mortality, cancer mortality, and cardiovascular mortality.

4. It is recommended that treatment is determined through sufficient discussion between the patient and physician about the benefits and risks associated with weight loss. While recommending treatments for obesity to patients, doctors must ensure that patients are ready to participate in weight loss.

5. It is recommended to lose $5 \%-10 \%$ of body weight within 6 months after starting treatment as the primary goal of weight loss.

B, Class lla

C, Class I

utrition therapy in obesity management

6. In order to lose weight, it is recommended that energy intake should be reduced, and the degree of energy restriction should be individualized according to individual characteristics and medical conditions.

7. Various dietary methods (low calorie diet, low carb diet, low fat diet, high protein diet) can be selected, but energy intake can be reduced, and nutritionally appropriate methods are recommended.

8. It is recommended to individualize the composition of macronutrients (carbohydrates, fats, proteins) according to individual characteristics and medical conditions

9. Very-low calorie diet should be implemented only in limited circumstances, and intensive interventions are recommended to be carried out to improve lifestyles along with medical monitoring.

Physical activity in obesity management

10. It is recommended to assess participation in physical activity and conduct health status evaluation before physical activity. In patients with symptoms of cardiovascular, metabolic, or kidney disease, it is recommended to start physical activity after consulting the patient's doctor. Otherwise, low to moderate intensity of physical activity is recommended initially.

11. For weight loss, it is recommended to perform aerobic exercise for at least 150 minutes per week or $3-5$ times a week. Additional resistance training 2-4 times a week using large muscle groups should be considered to lose weight.

A, Class I

A, Class lla

12. Physical activity alone does not have a great effect on weight loss, so we recommend physical activity combined with nutrition therapy.

A, Class I

13. For weight loss, a combination of aerobic exercise and resistance exercise should be considered because it is more effective than aerobic exercise alone and resistance exercise alone. There is no significant difference between high-intensity exercise and moderate-intensity

A, Class lla exercise in terms of weight loss effect.

Behavior therapy in obesity management

14. For weight loss, it is recommended to improve lifestyle through interventions such as reducing food intake and increasing physical activity.

A, Class I

15. For effective weight loss, it is recommended that a trained therapist performs behavior therapy for more than 6 months.

A, Class I

16. For effective weight maintenance, it is recommended that a trained therapist performs behavioral therapy for at least 1 year.

A, Class I

17. It is recommended that obese people be suspected to have eating disorders if they are observed with excessive weight or body type in

A, Class I self-assessment, various weight control behaviors to offset the effects of binge eating, or binge eating.

18. In the case of behavioral therapy for weight loss, smoking cessation counseling should be performed.

B, Class Ila

19. In the case of behavioral therapy for weight loss, we recommend alcohol counseling.

A, Class I

20. For the treatment of sleep apnea, it is recommended to lose weight through behavioral therapy.

A, Class I

Pharmacotherapy in obesity management

21. The basic treatments for obesity include nutrition therapy, physical activity, and behavior therapy, and we recommend pharmacotherapy as

A, Class I an additional treatment alongside comprehensive lifestyle intervention.

22. In cases of failure to lose weight through lifestyle intervention in patients with $B M I \geq 25 \mathrm{~kg} / \mathrm{m}^{2}$, pharmacotherapy should be considered.

23. For long-term weight management, it is recommended that drugs approved based on the large-scaled clinical trials should be used.

B, Class Ila

B, Class I

24. It is recommended that the pharmacotherapy be changed or discontinued if weight loss is not greater than $5 \%$ within 3 months of

A, Class I pharmacotherapy.

Bariatric surgery

25. Bariatric surgery should be considered to maintain weight loss and for weight loss in patients with severe obesity and to improve accompanying diseases related to obesity, including type 2 diabetes.

26. Bariatric surgery should be considered in patients with failure to lose weight despite optimal medical and behavioral management in whom

B, Class lla with $\mathrm{BMl} \geq 35 \mathrm{~kg} / \mathrm{m}^{2}$ or $\mathrm{BMl} \geq 30 \mathrm{~kg} / \mathrm{m}^{2}$ and obesity-related comorbidities. 
Table 2. Continued

Recommendation

27. Bariatric surgery should be considered in patients with type 2 diabetes with $\mathrm{BMl} \geq 27.5 \mathrm{~kg} / \mathrm{m}^{2}$ or poorly controlled blood glucose despite optimal medical management.

28. Sleeve gastrectomy, Roux-en-Y gastric bypass surgery, adjustable gastric band surgery, and biliopancreatic diversion surgery are standard procedures with established effectiveness and safety.

29. Before surgery, it is recommended to obtain past medical and psychosocial history and perform physical examination and diagnostic test to evaluate the safety of the surgery.

30. Preoperative micronutrient examination is required, and follow-up examination is recommended according to the schedule after the surgery

Category of evidence and

strength of recommendation

31. Multidisciplinary treatment should be considered before and after surgery to increase the treatment effectiveness and safety.

B, Class lla

A, Class I

A, Class I

A, Class I

Obesity in children and adolescents

32. It is recommended to prevent and treat childhood and adolescent obesity because they often develop into adult obesity and can cause accompanying diseases.

33. Treatment for childhood and adolescent obesity is recommended to provide the energy and nutrients needed for normal growth and maintain appropriate weight with proper lifestyle modifications.

34. When diagnosing obesity in children and adolescents over the age of 2, BMl percentiles by sex and age are based on the 2017 Child and Adolescent Growth Chart. BMI $\geq$ the 85th percentile is defined as pre-obesity, and $\geq$ the 95th percentile is defined as obesity.

35. Individualized risk assessment should be considered in children and adolescents with pre-obesity or obesity.

C, Class lla

36. For the treatment of obesity in children and adolescents, comprehensive lifestyle interventions including nutrition therapy, physical activity, and behavior therapy are recommended.

37. When comprehensive lifestyle interventions including nutrition therapy, physical activity, and behavior therapy fail to result in appropriate weight loss and comorbidities are not controlled, pharmacotherapy by an experienced specialist should be considered.

Obesity in the elderly

38. For diagnosis of obesity in the elderly, it is recommended to evaluate waist circumference along with BMI.

A, Class I

A, Class I

A, Class I

B, Class lla

A. Class I

B, Class lla

39. Weight loss in the elderly should be considered when the benefits of weight loss are greater than the status.

A, Class I

B, Class lla

40. In the treatment of obesity in the elderly, a protein-rich low-calorie diet and increased physical activity are recommended.

A, Class I

41. In the treatment of obesity in the elderly, pharmacotherapy and surgical treatment may be considered with regard to individual

B, Class llb comorbidities, other medications, and safety

Metabolic syndrome

42. As the severity of obesity increases, the incidence of metabolic syndrome increases.

A

43. The clinical significance of metabolic syndrome can predict the occurrence of diabetes and cardiovascular disease, and increases morbidity and mortality caused by cardiovascular disease

44. Diagnosis of metabolic syndrome in adults in Korea requires $\geq 3$ of the five following criteria: waist circumference $\geq 90 \mathrm{~cm}$ (men) or $\geq 85 \mathrm{~cm}$ (women), blood pressure $\geq 130 / 85 \mathrm{mmHg}$ or taking anti-hypertensive medication, fasting blood glucose $\geq 100 \mathrm{mg} / \mathrm{dL}$ or taking anti-diabetic medication, triglycerides $\geq 150 \mathrm{mg} / \mathrm{dL}, \mathrm{HDL}$ cholesterol $<40 \mathrm{mg} / \mathrm{dL}$ (men), or $50 \mathrm{mg} / \mathrm{dL}$ (women), or taking anti-dyslipidemia medication.

45. For the treatment of metabolic syndrome, lifestyle intervention and treatment of each component should be considered.

A, Class lla

BMI, body mass index; HDL, high-density lipoprotein.

the main users of the guideline, to make safer and more effective decisions by providing evidence-based recommendations with clear evidence levels and benefits. Second, it provides high-quality evidence-based information for primary care physicians.

\section{EVALUATION BEFORE OBESITY TREATMENT}

Diagnosis of obesity is important in the evaluation stage before obesity treatment. Body mass index (BMI), which is a value obtained by dividing body weight $(\mathrm{kg})$ by the square of height $\left(\mathrm{m}^{2}\right)$, is highly correlated with body fat mass, and because BMI can be used to evaluate health risks such as morbidity and mortality of obesity-associated diseases, BMI is the most commonly used index to diagnose obesity. The World Health Organization (WHO) defines obesity as BMI $\geq 30 \mathrm{~kg} / \mathrm{m}^{2}$. However, East Asians, including Koreans, have increased risk of diabetes and cardiovascular disease even below BMI of $25 \mathrm{~kg} / \mathrm{m}^{2}$ and higher abdominal fat and body fat percentages than Westerners at the same BMI. ${ }^{4}$ There is concern that the general $\mathrm{WHO}$ definition of obesity underestimates health risks associated with obesity in East Asians. The classification of obesity into classes I, II, and III relies on adult BMI in accor- 
Table 3. Definitions of obesity and risk of comorbidity according to obesity and abdominal obesity in Koreans

\begin{tabular}{lll}
\hline \multirow{2}{*}{ Classification } & \multicolumn{2}{c}{ Risk of comorbidity according to abdominal obesity } \\
\cline { 2 - 3 } & $\begin{array}{c}<90 \mathrm{~cm} \text { (men), } \\
<85 \mathrm{~cm} \text { (women) }\end{array}$ & $\begin{array}{r}\geq 90 \mathrm{~cm} \text { (men), } \\
\geq 85 \mathrm{~cm} \text { (women) }\end{array}$ \\
\hline BMl $\left(\mathrm{kg} / \mathrm{m}^{2}\right)$ & Low & Average \\
Underweight $(<18.5)$ & Average & Increased \\
Normal $(18.5-22.9)$ & Increased & High \\
Pre-obesity $(23.0-24.9)$ & High & Severe \\
Class I obesity $(25.0-29.9)$ & Severe & Very severe \\
Class II obesity $(30.0-34.9)$ & Very severe & Very severe \\
Class III obesity $(\geq 35.0)$ &
\end{tabular}

Pre-obesity may be defined as overweight or at-risk weight, and class III obesity may be defined as extreme obesity.

BMl, body mass index

dance with WHO guidelines for the Asia-Pacific region. ${ }^{5}$ Class I obesity is defined as BMI 25.0 to $29.9 \mathrm{~kg} / \mathrm{m}^{2}$, class II obesity is defined as BMI 30.0 to $34.9 \mathrm{~kg} / \mathrm{m}^{2}$, and class III obesity was newly defined in 2018 as $\geq 35.0 \mathrm{~kg} / \mathrm{m}^{2}$ (Table 3 ).

Waist circumference (WC) is highly associated with intra-abdominal fat. ${ }^{6} \mathrm{WC}$ is measured in the horizontal plane midway between the superior iliac crest and the lower margin of the last rib. ${ }^{7}$ According to the KSSO, abdominal obesity in Koreans is defined as WC $\geq 90 \mathrm{~cm}$ in men and $\geq 85 \mathrm{~cm}$ in women (Table 3 ). In the case of abdominal obesity, the morbidity and mortality of metabolic syndrome, diabetes, and coronary artery disease increase independently of BMI, so it is necessary to increase the risk of comorbidities classified by BMI to the next level (Table 3).

In some obese patients, secondary obesity is caused by genetic and congenital disorders, drugs, neurological and endocrine disorders, and psychiatric disorders. ${ }^{8}$ In patients with secondary obesity, relatively effective weight loss can be expected after accurate identification of the cause, so discerning secondary obesity is very important. Obesity causes metabolic abnormalities as well, and even if metabolic abnormalities are not present, obesity itself causes complications. Therefore, it is necessary to evaluate the comorbidities of obesity when treating obese patients.

\section{MEDICAL NUTRITION THERAPY}

To lose weight, it is necessary to reduce energy intake. Many weight control programs prescribe low-calorie diets that reduce en- ergy intake by $500-1,000 \mathrm{kcal}$, in which case a weight loss effect of $0.5-1.0 \mathrm{~kg}$ per week is expected. ${ }^{9}$ Therefore, based on the results of several studies, a low-calorie diet that reduces energy intake by 500-1,000 kcal per day can bring about weight loss without negative health effects and is also relatively easy to follow. Limiting total energy intake is important for the treatment of obesity, but there is a continuing interest in the effects of dietary macronutrients, especially carbohydrate composition, on weight loss. In the early 2000s, some randomized controlled studies reported that low-carb diets resulted in greater initial weight loss than traditionally recommended low-fat diets. ${ }^{10}$ The definition of a low-carbohydrate diet is not clear and varies according to researchers, but diets with daily carbohydrate intake of more than $130 \mathrm{~g}$ and less than $45 \%$ of total energy are classified as low-carbohydrate diets, while diets with a daily carbohydrate intake of less than $130 \mathrm{~g}$ are sometimes classified as verylow carbohydrate diets. ${ }^{11}$ Several studies indicated that low carbohydrate diets resulted in significantly greater weight loss during the initial 6 months compared to control diets. ${ }^{10,12,13}$ This difference from the control group persisted at 1 year, but compared to the initial 6 months, the difference was reduced. ${ }^{14-16}$

Increasing total fat intake through a very-low carbohydrate diet is likely to be accompanied by increased intake of saturated fatty acids and trans-fatty acids, and several studies report that such intake has negative effects on vasodilating capacity at the initiation of very-low carb diets. ${ }^{17-19}$ Adhering to a low-carb diet can be considered a method of weight loss, but is not effective in the long term and may negatively affect cardiovascular health, so it is necessary to pay special attention to fatty acid composition.

Consistently limiting energy intake can help in losing weight, but many individuals find it difficult to follow a strict energy-restricted diet. ${ }^{19}$ Interest in intermittent fasting as an alternative to sustained energy-restricted diets has increased. Intermittent fasting has many forms. Meta-analyses of intermittent fasting and time-limited diets suggest that these dietary methods can result in levels of weight loss effect equivalent to those accomplished via continuous energy-restricted diet, but related studies, especially regarding long-term effects, are insufficient. There is limited evidence to include intermittent fasting as a method of dietary treatment, and further studies are needed. The KSSO guidelines summarize the characteristics of each dietary treatment. ${ }^{20}$ 


\section{PHYSICAL ACTIVITY}

Exercise and physical activity are important factors in lifestyle interventions for weight loss. The weight loss effect of exercise rarely exceeds $5 \%$, but exercise and physical activity reduce the risks associated with various metabolic factors such as weight, body fat percentage, and visceral fat, and improves lean mass and functional ability. ${ }^{21,22}$ In addition, exercise with nutrition therapy has been found to be more effective than nutrition therapy alone, or exercise without nutrition therapy. ${ }^{23}$

In individuals with no cardiovascular, metabolic, or kidney disease, and no signs or symptoms, there is no need for medical permission before prescribing exercise for either regular exercise participants or non-participants. ${ }^{24}$ In accordance with the exercise guidelines, non-participants in regular exercise can start with low and moderate intensity exercise, while regular exercise participants may begin with moderate and high intensity exercise and gradually increase exercise intensity. Regular exercise participants with underlying cardiovascular (heart, peripheral artery, or cerebrovascular) disease, metabolic disease (type 1 or type 2 diabetes), or kidney disease, but who are asymptomatic, do not need medical permission to engage in moderate intensity exercise. Medical permission is recommended prior to high-intensity exercise. ${ }^{24}$

Aerobic exercise is an essential tool in weight loss programs addressing obesity. It is recommended to perform moderate-intensity exercise at least 150 minutes per week, 3-5 times a week, starting with low-intensity exercise and gradually increasing the intensity and amount of exercise according to individual fitness level. Resistance training should be prescribed in a weight loss exercise program to increase lean mass and promote body fat loss, and it is recommended to perform exercise using large muscle groups $2-4$ times a week. ${ }^{25}$

\section{BEHAVIOR THERAPY}

Behavior therapy can be applied not only as a programmed behavior intervention for weight control, but also for the purpose of changing behaviors related to food intake and physical activity. Treating obesity has long been known to be more effective when lifestyle interventions including behavioral therapy are performed.
Therefore, all obese people should undergo behavioral therapy, along with nutrition therapy and increased physical activity. Specific methods used in behavioral therapy include self-monitoring, reinforcement, stimulus control, alternative behavior, and cognitive reconstruction.

When treating obesity, it is very important to diagnose and treat any eating disorders that may exist. Eating disorders should be considered when binge eating, weight control behaviors to offset the effects of binge eating, and excessive emphasis on weight or body shape are observed in obese people. Obese people with eating disorders benefit from psychological therapies such as guided selfhelp or cognitive behavior therapy focused on eating disorders. ${ }^{26}$

When treating obesity, smoking and alcohol consumption must be reduced. Obese people should be advised to quit smoking. ${ }^{27} \mathrm{Al}-$ cohol has a high caloric content of about $7.1 \mathrm{kcal}$ per gram, and the liver produces fat in trace amounts. ${ }^{28,29}$ In addition, most ingested alcohol is converted to acetate, which interferes with peripheral fat breakdown and utilization. Clinically, alcohol raises blood pressure, and excessive drinking increases the risk of hypertriglyceridemia, insulin resistance, type 2 diabetes, metabolic syndrome, and abdominal obesity. Therefore, controlling excessive drinking is important for the prevention and control of obesity and metabolic syndrome. ${ }^{30}$

\section{PHARMACOTHERAPY}

The basic treatments for obesity are nutrition therapy, physical activity, and behavior therapy. We recommend pharmacotherapy as an additional treatment alongside comprehensive lifestyle intervention. According to the KSSO guideline, pharmacotherapy should be considered when non-pharmacotherapy-treated patients with BMI $\geq 25 \mathrm{~kg} / \mathrm{m}^{2}$ fail to lose weight (Fig. 1). Not all obese people respond to obesity drugs, and there are a significant number of nonresponders. A commonly used criterion for predicting treatment response is weight loss of $5 \%$ or more within the initial 3 months. If there is no weight loss of more than $5 \%$ within 3 months of initiating the drug, pharmacotherapy should be changed or discontinued.

As of 2020, four types of obesity treatments have been approved for long-term administration in Korea: orlistat (Xenical), naltrexone-bupropion (Contrave), liraglutide (Saxenda), and phenter- 


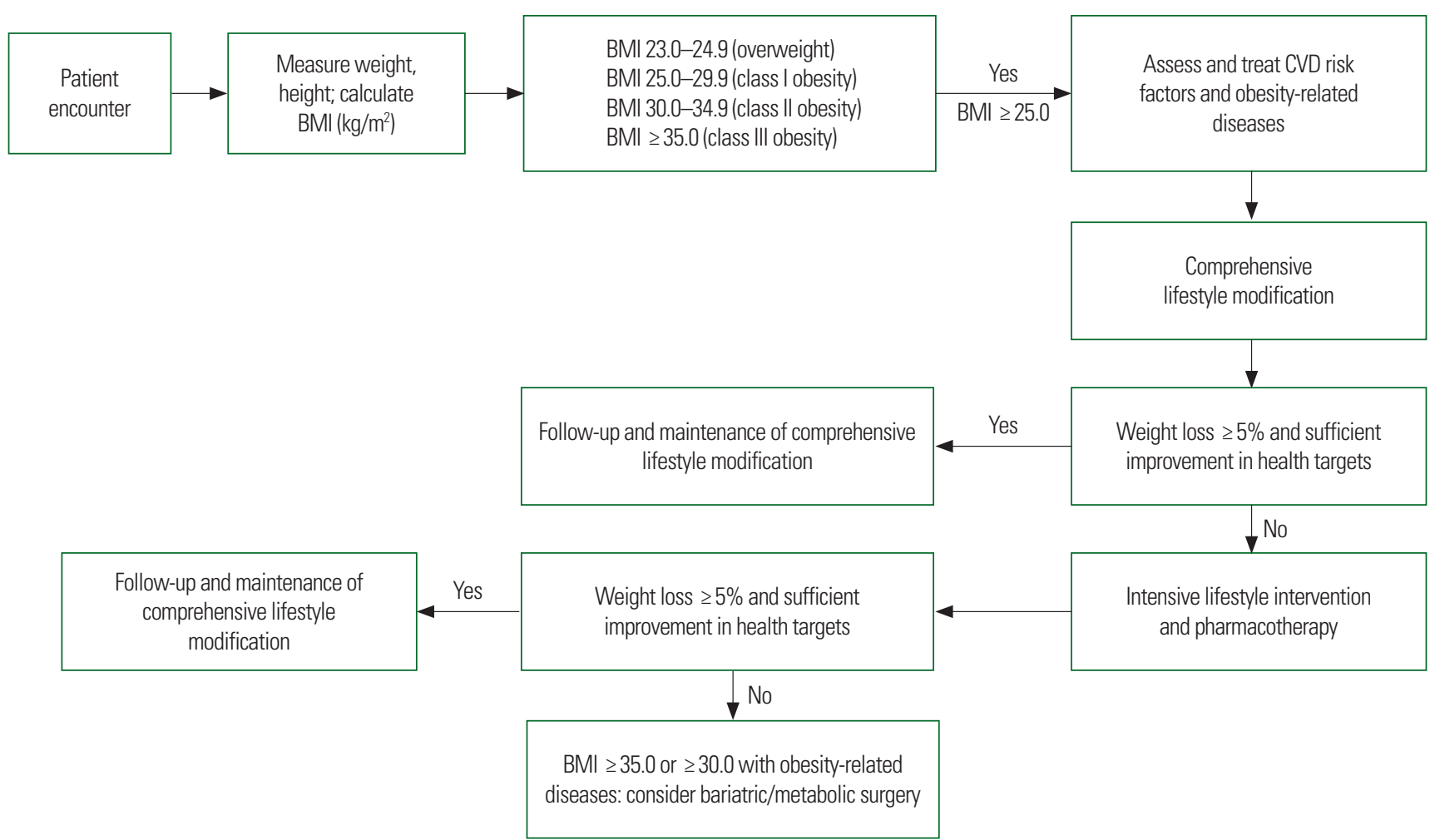

Figure 1. Treatment algorithm for the primary care of patients with obesity. BMI, body mass index; CVD, cardiovascular disease.

mine-topiramate (Qsymia). ${ }^{31}$ These drugs have been approved for use in the treatment of obesity based on the results of clinical studies on long-term use. Lorcaserin (Belviq) was used as a treatment for obesity from February 2015 to February 2020, but due to increased risk of cancer, it was voluntarily withdrawn from the market in the Unites States and discontinued from sales in Korea. ${ }^{32}$ These four drugs induce significant weight loss when administered together with lifestyle modifications, and result in improvement and prevention of various complications. Anti-obesity drugs must be prescribed according to the characteristics of each patient, and the presence of other comorbidities is important when choosing drugs. Table 4 guides the selection of anti-obesity drugs according to comorbidities.

\section{BARIATRIC SURGERY}

According to the International Federation for the Surgery of Obesity and Metabolic Disorders, Asian Pacific Chapter Consensus statements 2011(IFSO-APC consensus statements), ${ }^{33}$ the indications of bariatric surgery are failure to lose weight due to nonsurgi- cal treatment in patients with $\mathrm{BMI} \geq 35 \mathrm{~kg} / \mathrm{m}^{2}$ or BMI $\geq 30 \mathrm{~kg} / \mathrm{m}^{2}$ and obesity-related comorbidities, and this indication is applied in Korea. In Korea, from January 2019, the national health insurance plan has covered bariatric surgery performed for the purpose of treatment in patients with severe obesity. In patients with BMI $\geq 35 \mathrm{~kg} / \mathrm{m}^{2}$ or BMI $\geq 30 \mathrm{~kg} / \mathrm{m}^{2}$ and obesity-related comorbidities, health insurance benefits are applied.

Types of bariatric surgery can be largely divided into restrictive surgery, malabsorptive surgery, and combined surgery. Restrictive surgeries include sleeve gastrectomy and adjustable gastric banding, and malabsorptive surgery is defined as biliopancreatic diversion/duodenal switch (Table 5). The typical combined surgery is Roux-en-Y gastric bypass, which results in both restriction and absorption inhibition (Table 5). These surgeries are standard procedures that have already proven their effectiveness and safety, ${ }^{34}$ and since each surgical method has advantages and disadvantages, it is important to select an appropriate surgical method according to each patient's situation. In addition, in order to secure the safety and efficiency of patient management before and after surgery, collaboration across various departments is essential. 
Table 4. Individualization of anti-obesity medications

\begin{tabular}{|c|c|c|c|c|c|}
\hline \multirow{2}{*}{\multicolumn{2}{|c|}{ Coexisting disease }} & \multicolumn{4}{|c|}{ Anti-obesity medication } \\
\hline & & Orlistat & Naltrexone ER/bupropion ER & Liraglutide $3 \mathrm{mg}$ & Phentermine/topiramate ER \\
\hline \multicolumn{6}{|l|}{ Type 2 diabetes } \\
\hline \multirow{2}{*}{\multicolumn{2}{|c|}{ Hypertension }} & & $\begin{array}{l}\text { Monitor blood pressure and } \\
\text { heart rate }\end{array}$ & \multirow[t]{5}{*}{ Monitor heart rate } & Monitor heart rate \\
\hline & & & $\begin{array}{l}\text { Contraindicated in uncontrolled } \\
\text { hypertension }\end{array}$ & & \\
\hline $\begin{array}{l}\text { Coronary arterial } \\
\text { disease }\end{array}$ & & & $\begin{array}{l}\text { Monitor blood pressure and } \\
\text { heart rate }\end{array}$ & & \\
\hline \multirow{3}{*}{$\begin{array}{l}\text { Chronic kidney } \\
\text { disease }\end{array}$} & Mild (50-79 mL/min) & & & & \\
\hline & Moderate (30-49 mL/min) & & Do not exceed 8 mg/90 mg/day & & Do not exceed $7.5 \mathrm{mg} / 46 \mathrm{mg} / \mathrm{day}$ \\
\hline & Severe $(<30 \mathrm{~mL} / \mathrm{min})$ & Watch for oxalate stone & & & \\
\hline \multirow{2}{*}{$\begin{array}{l}\text { Hepatic } \\
\text { impairment }\end{array}$} & Mild-moderate (Child-Pugh 5-9) & Watch for cholelithiasis & Do not exceed 8 mg/90 mg/day & Watch for cholelithiasis & Do not exceed $7.5 \mathrm{mg} / 46 \mathrm{mg} / \mathrm{day}$ \\
\hline & Severe (Child-Pugh >9) & & & & \\
\hline \multicolumn{2}{|l|}{ Glaucoma } & & $\begin{array}{l}\text { Contraindicated, may trigger } \\
\text { angle closure }\end{array}$ & & $\begin{array}{l}\text { Contraindicated, may trigger } \\
\text { angle closure }\end{array}$ \\
\hline \multicolumn{2}{|l|}{ Pancreatitis } & & & $\begin{array}{l}\text { Avoid if prior or current } \\
\text { disease }\end{array}$ & \\
\hline
\end{tabular}

, preferred use; _ , use with caution; $\square$, avoid.

ER, extended release.

\section{OBESITY IN CHILDREN AND ADOLESCENTS}

Obesity in children and adolescents is rapidly increasing due to changes in diet, living environment, and decreases in physical activity. Obesity in children and adolescents is a chronic disease that is difficult to treat. It easily develops into adult obesity and requires a healthy diet and active lifestyle throughout life. Therefore, a policy of early detection and treatment should be established.

For the evaluation of obesity in children and adolescents, it is important to continuously evaluate obesity trends according to growth and development status through regular check-ups. ${ }^{35}$ The most widely used indicator is BMI. Percentile of BMI by sex and age is used to evaluate obesity in children and adolescents aged 2 years or older. In addition, since the growth and development period and body composition may differ depending on ancestry, standard values for Korean children and adolescents are applied. Age is calculated in months. ${ }^{35}$ Children or adolescents with BMI above the 85th percentile are considered overweight, those above the 95th percentile are obese, and those below the 85-95th percentile are regarded as pre-obesity. ${ }^{35}$

Considering the effects of obesity and obesity treatment on growth and development, it is important to prepare a treatment strategy for maintaining appropriate weight and avoiding unconditional weight loss. ${ }^{36-41}$ The key to the treatment of obesity in children and adolescents is to maintain an appropriate weight by inducing and continuing lifestyle modifications. Orlistat is the only drug approved by the U.S. Food and Drug Administration for usage by those over 12 years of age. ${ }^{42,43}$

\section{OBESITY IN THE ELDERLY}

Body weight is gained naturally with age and in the elderly, mortality does not increase with BMI $\geq 25 \mathrm{~kg} / \mathrm{m}^{2}$. The mortality rate in the elderly population is influenced not only by weight but also by other variables such as comorbidities. ${ }^{44}$ Therefore, for the diagnosis of obesity in the elderly, it is recommended to measure WC together with $\mathrm{BMI}$, and indicators such as the WC to height ratio and the WC to hip circumference ratio can also be utilized. ${ }^{45}$

Weight loss is recommended for elderly patients when it is judged that the benefits gained through weight loss during obesity treatment are greater than the harms. Even in the elderly, weight loss through lifestyle modifications such as diet control and physical activity is first considered and positive effects can be expected such as improving physical function and cardiovascular index. ${ }^{46}$

Well-designed studies of the effectiveness and safety of anti-obe- 
Table 5. Types of bariatric surgery

\begin{tabular}{|c|c|c|c|c|}
\hline & \multicolumn{4}{|c|}{ Type of surgery } \\
\hline & Adjustable gastric banding & Sleeve gastrectomy & Roux-en-Y gastric bypass & $\begin{array}{l}\text { Biliopancreatic diversion/ } \\
\text { duodenal switch }\end{array}$ \\
\hline \multicolumn{5}{|l|}{ Schematic diagram } \\
\hline History (yr) & 30 & $10-15$ & 50 (Most historical) & 20 \\
\hline Surgical technique & $\begin{array}{l}\text { Placement of an adjustable band } \\
\text { to retain a small amount of } \\
\text { gastric reservoir (15-20 mL) }\end{array}$ & $\begin{array}{l}\text { Longitudinal resection of the } \\
\text { stomach to achieve about } 80 \% \\
\text { gastric volume reduction }\end{array}$ & $\begin{array}{l}\text { Creation of small gastric pouch } \\
\text { (about } 30 \mathrm{~mL} \text { ) with diversion of } \\
\text { digestive pathway (bypassing } \\
\text { the residual stomach and upper } \\
\text { gastro-intestinal tract) }\end{array}$ & $\begin{array}{l}\text { Sleeve gastrectomy with } \\
\text { duodenal-ileal anastomosis } \\
\text { (bypassing the entire jejunum } \\
\text { and proximal part of ileum) }\end{array}$ \\
\hline Mechanism of weight loss & Intake restriction & Intake restriction & $\begin{array}{l}\text { Intake restriction (+absorption } \\
\text { restriction) }\end{array}$ & $\begin{array}{l}\text { Intake restriction+absorption } \\
\text { restriction }\end{array}$ \\
\hline Reversibility & Reversible & Irreversible & Partially reversible & Partially reversible \\
\hline $\begin{array}{l}\text { Effect of weight loss } \\
\text { (mid- to long-term \%EWL*) }\end{array}$ & $\begin{array}{l}2 \text { yr: } 50 \% \\
10 y r: 40 \%\end{array}$ & $\begin{array}{l}2 \text { yr: } 60 \% \\
10 \text { yr: } 50 \%-55 \%^{\dagger}\end{array}$ & $\begin{array}{l}2 \text { yr: } 70 \% \\
10 \text { yr: } 60 \%\end{array}$ & $\begin{array}{l}2 \text { yr: } 70 \%-80 \% \\
10 \text { yr: } 70 \%\end{array}$ \\
\hline $\begin{array}{l}\text { Advantages and } \\
\text { disadvantages, } \\
\text { Complications }\end{array}$ & $\begin{array}{l}\text { The frequency of implementation } \\
\text { is decreasing because of } \\
\text { relatively high incidence of } \\
\text { visceral complications related to } \\
\text { foreign material ( } 30 \%-40 \% \text { of } \\
\text { band removal or revisional } \\
\text { surgery is required within } \\
10 \text { years). }\end{array}$ & $\begin{array}{l}\text { Occurrence or deterioration of } \\
\text { gastro-esophageal reflux after } \\
\text { surgery } \\
\text { Relatively high incidence of weight } \\
\text { regain at long-term follow-up }\end{array}$ & $\begin{array}{l}\text { Difficulties in endoscopic screening } \\
\text { of the bypassed stomach } \\
\text { Risk of dumping syndrome and } \\
\text { marginal ulcer } \\
\text { Regular checkup and appropriate } \\
\text { supplementation is required for } \\
\text { prevention of trace element } \\
\text { deficiency }\end{array}$ & $\begin{array}{l}\text { Depletion of protein and trace } \\
\text { elements occurs frequently } \\
\text { Life-long supplementation of } \\
\text { deficient nutrients is needed }\end{array}$ \\
\hline
\end{tabular}

*Percentage of EWL: the rate of loss of excess weight based on body mass index of $25 \mathrm{~kg} / \mathrm{m}^{2}$; ${ }^{\dagger}$ Long-term follow-up data for more than 10 years is not yet sufficient. EWL, excess weight loss.

sity medications in the elderly are insufficient. Among drugs for obesity treatment approved for long-term use, orlistat can be safely used for elderly patients. ${ }^{47}$ Bariatric surgery in the elderly seems to be helpful for treating weight loss or diabetes, ${ }^{48,49}$ but caution is necessary because the risk of complications after surgery may increase. ${ }^{50}$

\section{METABOLIC SYNDROME}

Metabolic syndrome is the term for a combination of metabolic abnormalities such as hyperglycemia, high blood pressure (hypertension) and obesity. ${ }^{51}$ Diagnosis criteria for metabolic syndrome are in the process of being integrated, as different organizations have different criteria. International Diabetes Federation criteria for diagnosing metabolic syndrome begin with the recognition of abdominal obesity as the most important etiology, and therefore, ab- dominal obesity is an essential requirement for diagnosing metabolic syndrome. In addition, one of the main features is that it is recommended to use WC measurements suitable for different groups in recognition that the diagnostic criteria for abdominal obesity may differ by ancestry. In 2007, based on the results of the National Health and Nutrition Survey, Korea recognized abdominal obesity when the WC was more than $90 \mathrm{~cm}$ for men and $85 \mathrm{~cm}$ for women, ${ }^{52}$ and a recent study found that this criterion was appropriate for Koreans. Diagnosis of metabolic syndrome in Korean adults requires $\geq 3$ of the following five criteria: WC of $\geq 90 \mathrm{~cm}$ (men) or $\geq 85 \mathrm{~cm}$ (women), blood pressure $\geq 130 / 85 \mathrm{mmHg}$ or taking anti-hypertensive medication, fasting blood glucose $\geq 100 \mathrm{mg} / \mathrm{dL}$ or taking anti-diabetic medication, triglycerides $\geq 150 \mathrm{mg} / \mathrm{dL}$, and high-density lipoprotein cholesterol $<40 \mathrm{mg} / \mathrm{dL}$ (men) or $50 \mathrm{mg} / \mathrm{dL}$ (women) or taking anti-dyslipidemia medication. 
The goal of metabolic syndrome treatment is to prevent cardiocerebrovascular diseases and diabetes. There are two major therapeutic approaches to metabolic syndrome. One is lifestyle modification to reduce insulin resistance, which is the cause of metabolic syndrome, and the other is pharmacotherapy for each component of metabolic syndrome.

\section{CONCLUSION}

Obesity is a disease associated with increased socioeconomic burden due to increased risk of obesity-related comorbidities. Since obesity is multifactorial, treatments for obesity include comprehensive lifestyle interventions such as nutrition therapy, physical activity, behavior therapy, and pharmacotherapy. The proper surgical management of obesity requires a multidisciplinary treatment team. This new guideline helps primary care physicians make safer and more effective decisions by providing evidence-based recommendations with clear evidence levels and high-quality evidencebased information. More efforts are needed to improve the quality of obesity treatment and management in Korea.

\section{CONFLICTS OF INTEREST}

Ga Eun Nam has worked as an Associate Editor of the journal since 2020. However, she was not involved in the peer reviewer selection, evaluation, or decision process of this article. Otherwise, no other potential conflicts of interest relevant to this article were reported.

\section{ACKNOWLEDGMENTS}

This work was supported by the Korean Society for the Study of Obesity.

\section{AUTHOR CONTRIBUTIONS}

Study concept and design: BYK and CHK; acquisition of data: SMK, JHK (Jee-Hyun Kang), SYK, KKK, and BK; analysis and interpretation of data: SJK, YHK, JHK (Jae Hyun Kim), HL, EJJ, SC, KBK, YAS and YHH; drafting of the manuscript: BYK and
CHK; critical revision of the manuscript: BYK, EMK, SMK, JHK (Jee-Hyun Kang), SYK, KKK, BK, SJK, YHK, JHK (Jung-Hwan Kim), JHK (Jae Hyun Kim), GEN, JYP, JWS, HJS, TJO, HL, EJJ, SC, YHH, YAS and CHK; statistical analysis: SJK, YHK, and JHK (Jung-Hwan Kim); obtained funding: BYK and CHK; administrative, technical, or material support: BYK and CHK; and study supervision: $\mathrm{CHK}$.

\section{REFERENCES}

1. Nam GE, Kim YH, Han K, Jung JH, Rhee EJ, Lee SS, et al. Obesity fact sheet in Korea, 2019: prevalence of obesity and abdominal obesity from 2009 to 2018 and social factors. J Obes Metab Syndr 2020;29:124-32.

2. Seo MH, Lee WY, Kim SS, Kang JH, Kang JH, Kim KK, et al. 2018 Korean Society for the Study of Obesity guideline for the management of obesity in Korea. J Obes Metab Syndr 2019;28:40-5.

3. Schünemann HJ, Wiercioch W, Brozek J, Etxeandia-Ikobaltzeta I, Mustafa RA, Manja V, et al. GRADE Evidence to Decision (EtD) frameworks for adoption, adaptation, and de novo development of trustworthy recommendations: GRADEADOLOPMENT. J Clin Epidemiol 2017;81:101-10.

4. Seo MH, Kim YH, Han K, Jung JH, Park YG, Lee SS, et al. Prevalence of obesity and incidence of obesity-related comorbidities in Koreans based on National Health Insurance Service health checkup data 2006-2015. J Obes Metab Syndr 2018;27:46-52.

5. Deurenberg P, Deurenberg-Yap M, Guricci S. Asians are different from Caucasians and from each other in their body mass index/body fat per cent relationship. Obes Rev 2002;3: 141-6.

6. Yumuk V, Tsigos C, Fried M, Schindler K, Busetto L, Micic D, et al. European Guidelines for Obesity Management in Adults. Obes Facts 2015;8:402-24.

7. Obesity: preventing and managing the global epidemic. Report of a WHO consultation. World Health Organ Tech Rep Ser 2000;894:i-xii, 1-253.

8. Rosenbaum M, Leibel RL, Hirsch J. Obesity. N Engl J Med 1997;337:396-407. 


\section{American College of Cardiology/American Heart Association} Task Force on Practice Guidelines, Obesity Expert Panel, 2013. Expert Panel Report: Guidelines (2013) for the management of overweight and obesity in adults. Obesity (Silver Spring) 2014;22 Suppl 2:S41-410.

10. Foster GD, Wyatt HR, Hill JO, McGuckin BG, Brill C, Mohammed BS, et al. A randomized trial of a low-carbohydrate diet for obesity. N Engl J Med 2003;348:2082-90.

11. Hite AH, Berkowitz VG, Berkowitz K. Low-carbohydrate diet review: shifting the paradigm. Nutr Clin Pract 2011;26: 300-8.

12. Shai I, Schwarzfuchs D, Henkin Y, Shahar DR, Witkow S, Greenberg I, et al. Weight loss with a low-carbohydrate, Mediterranean, or low-fat diet. N Engl J Med 2008;359:229-41.

13. Yancy WS Jr, Olsen MK, Guyton JR, Bakst RP, Westman EC. A low-carbohydrate, ketogenic diet versus a low-fat diet to treat obesity and hyperlipidemia: a randomized, controlled trial. Ann Intern Med 2004;140:769-77.

14. Sacks FM, Bray GA, Carey VJ, Smith SR, Ryan DH, Anton $\mathrm{SD}$, et al. Comparison of weight-loss diets with different compositions of fat, protein, and carbohydrates. $\mathrm{N}$ Engl J Med 2009;360:859-73.

15. Dong T, Guo M, Zhang P, Sun G, Chen B. The effects of low-carbohydrate diets on cardiovascular risk factors: a metaanalysis. PLoS One 2020;15:e0225348.

16. Tobias DK, Chen M, Manson JE, Ludwig DS, Willett W, Hu FB. Effect of low-fat diet interventions versus other diet interventions on long-term weight change in adults: a systematic review and meta-analysis. Lancet Diabetes Endocrinol 2015; 3:968-79.

17. Wekesa AL, Doyle LM, Fitzmaurice D, O’Donovan O, Phelan JP, Ross MD, et al. Influence of a low-carbohydrate diet on endothelial microvesicles in overweight women. Appl Physiol Nutr Metab 2016;41:522-7.

18. Phillips SA, Jurva JW, Syed AQ, Syed AQ, Kulinski JP, Pleuss J, et al. Benefit of low-fat over low-carbohydrate diet on endothelial health in obesity. Hypertension 2008;51:376-82.

19. Buscemi S, Verga S, Tranchina MR, Cottone S, Cerasola G. Effects of hypocaloric very-low-carbohydrate diet vs. Mediterranean diet on endothelial function in obese women. Eur J
Clin Invest 2009;39:339-47.

20. Committee of Clinical Practice Guidelines; Korean Society for the Study of Obesity. 2020 Korean Society for the Study of Obesity (KSSO) Guideline for the Management of Obesity in Korea. Seoul: Korean Society for the Study of Obesity; 2020.

21. Ashutosh K, Methrotra K, Fragale-Jackson J. Effects of sustained weight loss and exercise on aerobic fitness in obese women. J Sports Med Phys Fitness 1997;37:252-7.

22. Dengel DR, Hagberg JM, Coon PJ, Drinkwater DT, Goldberg AP. Effects of weight loss by diet alone or combined with aerobic exercise on body composition in older obese men. Metabolism 1994;43:867-71.

23. Kim KB, Kim K, Kim C, Kang SJ, Kim HJ, Yoon S, et al. Effects of exercise on the body composition and lipid profile of individuals with obesity: a systematic review and meta-analysis. J Obes Metab Syndr 2019;28:278-94.

24. American College of Sports Medicine. ACSM's exercise testing and prescription. 10th. Philadelphia (PA): Lippincott Williams \& Wilkins; 2017.

25. Donnelly JE, Blair SN, Jakicic JM, Manore MM, Rankin JW, Smith BK, et al. American College of Sports Medicine Position Stand: appropriate physical activity intervention strategies for weight loss and prevention of weight regain for adults. Med Sci Sports Exerc 2009;41:459-71.

26. Bray GA, Heisel WE, Afshin A, Jensen MD, Dietz WH, Long $\mathrm{M}$, et al. The science of obesity management: an Endocrine Society scientific statement. Endocr Rev 2018;39:79-132.

27. Chiolero A, Faeh D, Paccaud F, Cornuz J. Consequences of smoking for body weight, body fat distribution, and insulin resistance. Am J Clin Nutr 2008;87:801-9.

28. Suter PM, Häsler E, Vetter W. Effects of alcohol on energy metabolism and body weight regulation: is alcohol a risk factor for obesity? Nutr Rev 1997;55:157-71.

29. Yeomans MR. Alcohol, appetite and energy balance: is alcohol intake a risk factor for obesity? Physiol Behav 2010;100:82-9.

30. Baliunas DO, Taylor BJ, Irving H, Roerecke M, Patra J, Mohapatra S, et al. Alcohol as a risk factor for type 2 diabetes: a systematic review and meta-analysis. Diabetes Care 2009;32: 2123-32. 
31. Kim BY, Kang SM, Kang JH, Kim KK, Kim B, Kim SJ, et al. Current long-term pharmacotherapies for the management of obesity. J Obes Metab Syndr 2020;29:99-109.

32. U.S. Food and Drug Administration. FDA requests the withdrawal of the weight-loss drug Belviq, Belviq XR (lorcaserin) from the market [Internet]. Silver Spring, MD: U.S. Food and Drug Administration; 2020 [cited 2020 April 5]. Available from: https://www.fda.gov/drugs/drug-safety-and-availability/fda-requests-withdrawal-weight-loss-drug-belviq-belviq-xr-lorcaserin-market.

33. Kasama K, Mui W, Lee WJ, Lakdawala M, Naitoh T, Seki Y, et al. IFSO-APC consensus statements 2011. Obes Surg 2012; 22:677-84.

34. Padwal R, Klarenbach S, Wiebe N, Birch D, Karmali S, Manns $B$, et al. Bariatric surgery: a systematic review and network meta-analysis of randomized trials. Obes Rev 2011;12:602-21.

35. Korea Disease Control and Prevention Agency. Growth charts for children and adolescents. Cheongju: Korea Disease Control and Prevention Agency; 2017.

36. Styne DM, Arslanian SA, Connor EL, Farooqi IS, Murad MH, Silverstein JH, et al. Pediatric obesity-assessment, treatment, and prevention: an Endocrine Society clinical practice guideline. J Clin Endocrinol Metab 2017;102:709-57.

37. US Preventive Services Task Force, Barton M. Screening for obesity in children and adolescents: US Preventive Services Task Force recommendation statement. Pediatrics 2010;125: 361-7.

38. Barlow SE; Expert Committee. Expert committee recommendations regarding the prevention, assessment, and treatment of child and adolescent overweight and obesity: summary report. Pediatrics 2007;120 Suppl 4:S164-92.

39. Speiser PW, Rudolf MC, Anhalt H, Camacho-Hubner C, Chiarelli F, Eliakim A, et al. Childhood obesity. J Clin Endocrinol Metab 2005;90:1871-87.

40. Zwiauer KF. Prevention and treatment of overweight and obesity in children and adolescents. Eur J Pediatr 2000;159 Suppl 1:S56-68.

41. Chao AM, Wadden TA, Berkowitz RI. The safety of pharmacologic treatment for pediatric obesity. Expert Opin Drug Saf 2018; 17:379-85.
42. Chanoine JP, Hampl S, Jensen C, Boldrin M, Hauptman J. Effect of orlistat on weight and body composition in obese adolescents: a randomized controlled trial. JAMA 2005;293: 2873-83.

43. Matson KL, Fallon RM. Treatment of obesity in children and adolescents. J Pediatr Pharmacol Ther 2012;17:45-57.

44. Jee SH, Sull JW, Park J, Lee SY, Ohrr H, Guallar E, et al. Bodymass index and mortality in Korean men and women. N Engl J Med 2006;355:779-87.

45. Zaslavsky O, Rillamas-Sun E, LaCroix AZ, Woods NF, Tinker LF, Zisberg A, et al. Association between anthropometric measures and long-term survival in frail older women: observations from the women's health initiative study. J Am Geriatr Soc 2016;64:277-84.

46. Rejeski WJ, Marsh AP, Chmelo E, Rejeski JJ. Obesity, intentional weight loss and physical disability in older adults. Obes Rev 2010;11:671-85.

47. Mathus-Vliegen EM; Obesity Management Task Force of the European Association for the Study of Obesity. Prevalence, pathophysiology, health consequences and treatment options of obesity in the elderly: a guideline. Obes Facts 2012;5: 460-83.

48. Daigle CR, Andalib A, Corcelles R, Cetin D, Schauer PR, Brethauer SA. Bariatric and metabolic outcomes in the superobese elderly. Surg Obes Relat Dis 2016;12:132-7.

49. Yoon J, Sherman J, Argiroff A, Chin E, Herron D, Inabnet W, et al. Laparoscopic sleeve gastrectomy and gastric bypass for the aging population. Obes Surg 2016;26:2611-5.

50. Marczuk P, Kubisa MJ, Święch M, Walędziak M, Kowalewski P, Major P, et al. Effectiveness and safety of Roux-en-Y gastric bypass in elderly patients-systematic review and meta-analysis. Obes Surg 2019;29:361-8.

51. DeFronzo RA, Ferrannini E. Insulin resistance: a multifaceted syndrome responsible for NIDDM, obesity, hypertension, dyslipidemia, and atherosclerotic cardiovascular disease. Diabetes Care 1991;14:173-94.

52. Lee SY, Park HS, Kim DJ, Han JH, Kim SM, Cho GJ, et al. Appropriate waist circumference cutoff points for central obesity in Korean adults. Diabetes Res Clin Pract 2007;75: 72-80. 